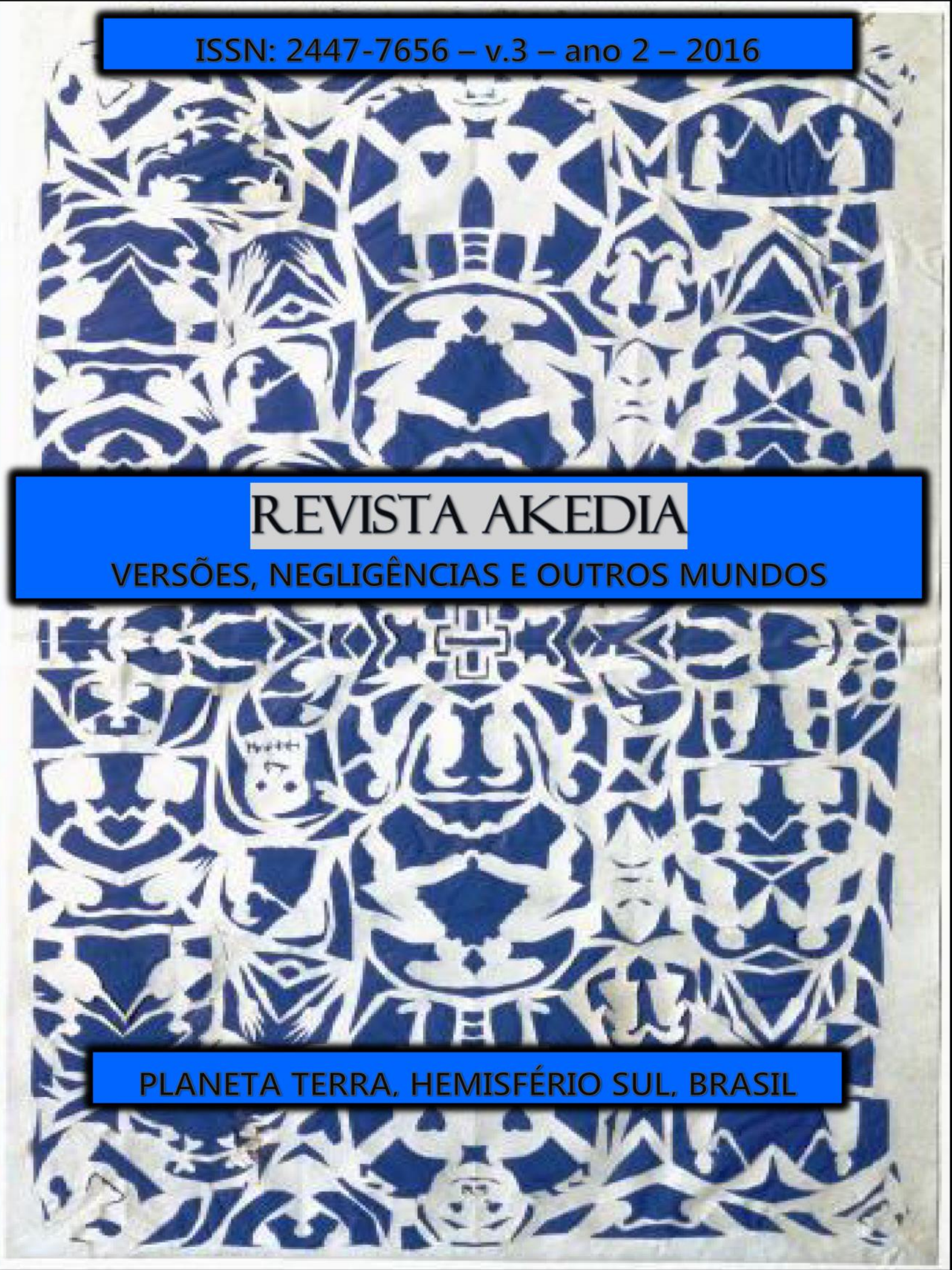




\section{TEXTO AKEDIANO PARA ESTE VOLUME}

E eu, tantas vezes reles, tantas vezes porco, tantas vezes vil,

Eu, tantas vezes irrespondivelmente parasita, Indesculpavelmente sujo,

Eu, que tantas vezes não tenho tido paciência para tomar banho,

Eu, que tantas vezes tenho sido ridículo, absurdo,

Que tenho enrolado os pés publicamente nos tapetes das etiquetas,

Que tenho sido grotesco, mesquinho, submisso e arrogante,

Que tenho sofrido enxovalhos e calado,

Que quando não tenho calado, tenho sido mais ridículo ainda.

$\mathrm{Eu}$, que tenho sido cômico às criadas de hotel,

Eu, que tenho sentido o piscar de olhos dos moços de fretes,

$\mathrm{Eu}$, que tenho feito vergonhas financeiras, pedido emprestado sem pagar,

Eu, que, quando a hora do soco surgiu, me tenho agachado

Para fora da possibilidade do soco.

$\mathrm{Eu}$, que tenho sofrido a angústia das pequenas coisas ridículas,

Eu verifico que não tenho par nisto tudo neste mundo.

(Fragmento de: Poema em Linha Reta, Fernando Pessoa, sob o pseud. Álvaro de Campos)

\section{GRUPO DE PESQUISA SOCIEDADE, IMAGENS E CULTURA (SIC)}

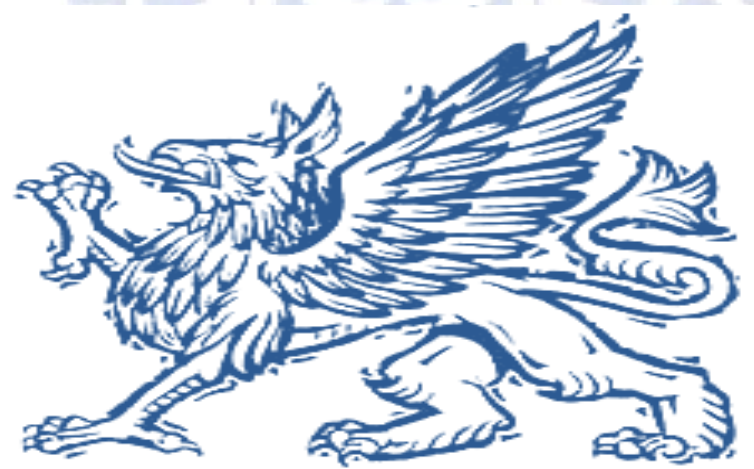

VOLUME III

UNIVERSIDADE

DO ESTADO DE MINAS GERAIS

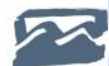

UEMG

UNIDADE FRUTAL 


\section{GRUPO DE PESQUISA SOCIEDADE, IMAGENS E CULTURA (SIC)}

\section{AKEDIA - VERSÕES, NEGLIGÊNCIAS E OUTROS MUNDOS}

VOLUME III

CIÊNCIAS HUMANAS E CIÊNCIAS SOCIAIS

\section{FRUTAL - MG 2016}




\section{Equipe de Revisão \\ Dr. Marcelo Pessoa \\ Arianne Moraes - Publicitária \\ Diagramação e Arte \\ Dr. Marcelo Pessoa \\ Capa}

Autor: Hans Christian Andersen

Título: "Fantasy cutting for Dorothea" (corte de fantasia para Dorothea)

Disponível em:

http://www.dominiopublico.gov.br/pesquisa/DetalheObraForm.do?select action=\&co obra= $\underline{5723}$

Acesso em 25/01/2016.

\section{Impressão e Hospedagem Eletrônica do Volume}

http://mpmarcelopessoa.wixsite.com/akediaonline

\section{Editor Corporativo}

Grupo de Pesquisas Sociedade, Imagens e Cultura (SIC)

\section{Editor Responsável}

Prof. Dr. Marcelo Pessoa

\section{Conselho Editorial}

Dr. Dionísio Vila Maior (UAL, Lisboa)

Dr. Rodrigo Ney Millan (UEMG, Frutal)

Dr. Andrés Alberto Donoso Romo (UPLA, Chile)

Dr. Allynson Takehiro Fujita (UEMG, Frutal)

Dra. Cintia Camargo Vianna (UFU, Uberlândia)

Dr. Marcelo Pessoa (UEMG, Frutal)

Dr. Jorge Pedro Sousa (Universidade do Porto, Portugal)

Dra. Daniela Soares Portela (UEMG, Frutal)

Dr. André Vinicius Martinez Gonçalves (IFG, Goiás)

Dra. Cristiane Pimentel Neder (UEMG, Frutal)

\section{P475p Pessoa, Marcelo}

Grupo de Pesquisa Sociedade, Imagens e Cultura (SIC). / Marcelo Pessoa (org.) -- Frutal, 2016.

148 f.: il., (vol. de Pesquisa Básica e Avançada).

ISSN 2447-7656

DOI NUMBER 10.33726

1. Produção científica. 2. Homem. 3. Cultura. 4. Sociedade I. Pessoa, Marcelo. II. Universidade do Estado de Minas Gerais. III. Título. 


\section{EDITORIAL}

É COM GRANDE SATISFAÇÃO QUE, NESTE MÊS DE DEZEMBRO DE 2016, DIVULGAMOS O TERCEIRO VOLUME DA REVISTA “AKEDIA: VERSÕES, NEGLIGÊNCIAS E OUTROS MUNDOS".

CONCEBIDA ORIGINALMENTE, NA SEGUNDA METADE DE 2015, PARA SER UMA PUBLICAÇÃO IMPRESSA, ESTA MÍDIA CIENTÍFICA, ALINHADA ÀS DEMANDAS TÉCNICAS DE SEU TEMPO, RAPIDAMENTE PASSOU A INTEGRAR REPOSITÓRIOS DIGITAIS COMO O DO SITE DA UEMG - UNIVERSIDADE DO ESTADO DE MINAS GERAIS, UNIDADE FRUTAL, SENDO LOGO, EM 2016, EMBARCADA NO SEU PRÓPRIO SÍTIO, VIA PLATAFORMA WIX.COM.

COM PREVISÃO DE PERIODICIDADE SEMESTRAL, O FLUXO EDITORIAL DA "REVISTA AKEDIA" É GERENCIADO PELO EDITOR RESPONSÁVEL, QUE TAMBÉM ÉLÍDER DO GRUPO DE PESQUISAS SOCIEDADE, IMAGENS E CULTURA (SIC).

A COMPOSIÇÃO DO CORPO EDITORIAL CONTA COM A PARTICIPAÇÃO DE PROFESSORES DE INSTITUIÇÕES BRASILEIRAS E DE OUTROS PAÍSES, OS QUAIS ATUARÃOO, SEMPRE QUE SOLICITADOS, COMO CONSULTORES AD HOC, DIRIMINDO QUESTÕES AS QUAIS, SEM SEU KNOW HOW ACUMULADO A SOLUÇÃO NÃO SE DARIA A CONTENTO.

CENTRADA NAS PREOCUPAÇÕES ASSOCIADAS ÀS CIÊNCIAS HUMANAS, ESTA REVISTA, BEM COMO AS DEMAIS PUBLICAÇÕES CIENTÍFICAS DO SIC, APESAR DE TAL PREMISSA, NÃO SE ATÉM OBRIGATORIAMENTE À ESPÉCIE CONCEITUAL QUE SE EVOCA PARA ESTA OU AQUELA ÁREA DO CONHECIMENTO. SIMULTANEAMENTE, NOSSAS PUBLICAÇÕES NÃO SE PROPÕEM INTERDISCIPLINARES, VISTO QUE SERIA PARADOXAL ROMPER COM UMA TRADIÇÃO E ADERIR À OUTRA.

É FATO, POR ISSO, QUE AS PUBLICAÇÕES DITAS, ASSIM, AKEDIANAS, SÃO CONTROVERSAS, UMA VEZ QUE ORIENTA NOSSO CORPO EDITORIAL O DESEJO DE REUNIR E DIVULGAR TEXTOS QUE TRATEM DOS ASPECTOS CONTRADITÓRIOS HUMANOS, SOCIAIS E CULTURAIS QUE CONSTITUAM NOSSA CIVILIZAÇÃO, ACENANDO PARA UM TERRITÓRIO DE REFLEXÕES E DE FRONTEIRAS VISÍVEIS, PORÉM, MÓVEIS.

NESTA CESTA DE LETRAS, PORTANTO, CABE TODA PONDERAÇÃO QUE SE CONCEBA NO MUNDO, POR MEIO DE DIÁLOGOS RECÍPR OCOS ENTRE O ORGÂNICO E O INÔRGÂNICO, ENTRE O POLÍTICO E O CULTURAL, ENTRE O MICROSCÓPICO E O 
MACROSCÓPICO, ENTRE O ECONÔMICO E O SOCIAL, ENTRE O TÁTIL E O INVISÍVEL, POIS, EM SUMA:

\begin{abstract}
A NATUREZA COMPLEXA DE TAIS PROBLEMAS PEDE DIÁLOGOS NÃO SÓ ENTRE DISCIPLINAS PRÓXIMAS, DENTRO DA MESMA ÁREA DO CONHECIMENTO, MAS ENTRE DISCIPLINAS DE ÁREAS DIFERENTES, BEM COMO ENTRE SABERES DISCIPLINARES E SABERES NÃO DISCIPLINARES DA SOCIEDADE E DAS CULTURAS, DEPENDENDO DO NÍVEL DE COMPLEXIDADE DO FENÔMENO A SER TRATADO. DAÍ, A RELEVÂNCIA, NO MUNDO CONTEMPORÂNEO, DE NOVAS FORMAS DE PRODUÇÃO DO CONHECIMENTO QUE TOMAM COMO OBJETO FENÔMENOS QUE SE COLOCAM ENTRE FRONTEIRAS DISCIPLINARES, QUANDO A COMPLEXIDADE DO PROBLEMA REQUER DIÁLOGO ENTRE E ALÉM DAS DISCIPLINAS. DIANTE DISSO, DESAFIOS TEÓRICOS E METODOLÓGICOS COLOCAM-SE PARA DIFERENTES CAMPOS DA CIÊNCIA E DA TECNOLOGIA (CAPES, DOCUMENTO DE ÁREA 2009. DISPONIVEL

HTTPS./NWWW.CAPES.GOV.BR/MAGES/STORIES/DOWNLOAD/AVALI ACAO/NTER03AGOIO.PDF, ACESSO EM 06/05/2015).
\end{abstract}

FINALMENTE, VALE DIZER QUE, NESTE ESPAÇO DE DIVULGAÇÃO CIENTÍFICA, SE PUBLICARÃO NOS PRIMEIROS TRÊS VOLUMES, TEXTOS DE INTEGRANTES DO SIC. E NÃO APENAS ESTES, POIS, A PRODUÇÃO DOCENTE, A PUBLICAÇÃO DISCENTE E DOS SERVIDORES DA UEMG - UNIVERSIDADE DO ESTADO DE MINAS GERAIS, UNIDADE FRUTAL, OU DE OUTRAS INSTITUIÇÕES INDICADAS POR MEMBROS DE NOSSO CONSELHO EDITORIAL NOS SERÃO TAMBÉM OBJETOS PREFERENCIAIS, DESDE QUE FRUTOS DE PESQUISAS DEVIDAMENTE ORIENTADAS, E QUE SE CONECTEM COM A LINHA DE PENSAMENTO DE NOSSO CORPO EDITORIAL, BEM COMO AOS DITAMES ALUDIDOS ANTERIORMENTE PELA COORDENADORIA DE APERFEIÇOAMENTO DE PESSOAL DE ENSINO SUPERIOR - CAPES.

MARCELO PESSOA (EDITOR RESPONSÁVEL E LÍDER DO GRUPO SIC) 


\section{PREFÁCIO À 3ª EDIÇÃO}

NO TERCEIRO VOLUME DA REVISTA "AKEDIA: VERSÕES, NEGLIGÊNCIAS E OUTROS MUNDOS”, APRESENTAMOS AOS LEITORES UMA PREOCUPAÇÃO: LEGITIMAR OU NÃO ESTA REVISTA COM A CHANCELA “QUALIS CAPES”, VISTO QUE A PARTIR DA PUBLICAÇÃO DO TERCEIRO NÚMERO DAS PUBLICAÇÕES É QUE SE PODE REQUERER À CAPES TAL RECONHECIMENTO?

MAS, QUAL A RAZÃO DE TECERMOS UMA LINHA DE RACIOCÍNIO, A QUAL SE REVELA APARENTEMENTE OPOSTA A TUDO O QUE SE PRECONIZA NA ACADEMIA? SIM, POIS, EM SÃ CONSCIÊNCIA, QUEM SE LEVANTARIA EM ATITUDE CONTRÁRIA À TUTELA CAPES E, PORTANTO, À SOLICITAÇÃO DE TAL REFERENDO?

COMO EDITOR DA REVISTA AKEDIA TENHO REFLETIDO SINCERAMENTE SOBRE ESTAS QUESTÕES DESDE A CONCEPÇÃO EDITORIAL DA REVISTA, FACE AO CARÁTER FORDISTA IMPOSTO À PRODUÇÃO ACADÊMICA. DESSE MODO, A CIÊNCIA DE HOJE MENOS SE REVELA PELA QUALIDADE DO CONHECIMENTO QUE PRODUZ, E MAIS PELO INTENSO DESGASTE QUE TEM SIDO IMPOSTO AOS CIENTISTAS DE TODAS AS ÁREAS, OS QUAIS AINDA SE VEEM ATOLADOS PELO TRABALHO EM SALA DE AULA. ESTES MESMOS PROFISSIONAIS TAMBÉM VIVEM ATAREFADOS E EXTREMAMENTE ENVOLVIDOS COM O EXCESSIVO APARATO BUROCRÁTICO QUE SE APODEROU DO MEIO ACADÊMICO.

AO REPENSARMOS A CHANCELA QUALIS, O QUE QUEREMOS É PROPOR AO CENÁRIO DA CIÊNCIA UMA ALTERNATIVA, EM QUE AS PUBLICAÇÕES SEJAM DOTADAS DE QUALIDADES TEXTUAIS E DE CONTEÚDOS, SEM QUE NECESSARIAMENTE SEJAM REPETIDORAS OU DEPENDENTES DE UMA ESTRUTURA DE LEGITIMAÇÃO QUE, NO FUNDO, SE IMPÕE COMO PODER, E NÃO COMO EMPODERAMENTO, O QUE, A NOSSO VER, É COMO DEVERIA SER. 
SUMÁRIO

RESUMOS

1. ADMINISTRAÇÃO DA EMPRESA FAMILIAR NO RAMO ALIMENTÍCIO: O CASE DO WAL-MART.

2. A EVOLUÇÃO DA ESCRITA NO CONTEXTO DO ENSINO 16

3. A MULHER EMPREENDEDORA: POR DENTRO DE UM MERCADO DE TRABALHO NO SETOR INDUSTRIAL DE EXPORTAÇÃO.

4. EMPREENDEDORISMO NO AGRONEGÓCIO .18

5. EVOLUÇÃO TECNOLÓGICA versus EVOLUÇÃO DA ESCRITA........19

6. GESTÃO AMBIENTAL NO SETOR PÚBLICO MUNICIPAL DA CIDADE DE FRUTAL - MG. 20

7. GESTÃO DE RISCO NA BOLSA DE VALORES. 21

8. LIBRAS: INCLUSÃO PARA DENTRO OU INCLUSÃO PARA FORA.

9. MARKETING DO ORLANDO CITY SOCCER CLUB: A EVOLUÇÃO DO TIME

10. MARKETING-PATROCÍNIO: A PRIMEIRA DIVISÃO DO

CAMPEONATO BRASILEIRO DE FUTEBOL

11. O DESAFIO DA TRANSIÇÃO OPERACIONAL DA EMPRESA

FAMILIAR.

12. O DESENVOLVIMENTO DAS MICROEMPRESAS NO SETOR ALIMENTÍCIO.

13. O ESTUDO DA ADMINISTRAÇÃO EM MICRO E PEQUENAS EMPRESAS NO SETOR PESQUEIRO

14. OS ASPECTOS DA CRISE NO CENÁRIO ECONÔMICO COMERCIAL FRUTALENSE: UMA ANÁLISE COMPARATIVA ENTRE O 1은 SEMESTRE DOS ANOS DE 2014, 2015 e 2016. 
15. REGRAS GERAIS DO MARKETING.

16. SOCIEDADE DO ESTRESSE: UM OLHAR QUALITATIVO SOBRE A VIDA.

17. A HISTÓRIA DA TECNOLOGIA NA EDUCAÇÃO. 31

18. A HISTÓRIA DA TECNOLOGIA versus EVOLUÇÃO NA COMUNICAÇÃO

\section{ARTIGOS}

1. DIREITO, EDUCAÇÃO E CULTURA: UM ENFOQUE SOBRE A LDB (LEI 9394/96) CAROLINA MAIA SOARES SILVA; MARCELO PESSOA

2. COMO OS UNIVERSITÁRIOS DO CURSO DE DIREITO E ADMINISTRAÇÃO DA UEMG UNIDADE FRUTAL LIDAM COM SUAS FINANÇAS PESSOAIS? - MÔNICA QUEIROZ DA SILVA

3. CONFLITOS NO USO DA LINGUAGEM NA TECNOMEDIAÇÃO: DIÁLOGOS SOBRE EDUCAÇÃO, ESPAÇO E CULTURA - MARCELO PESSOA.

4. O PROFISSIONAL DE COACHING E SEU DIA A DIA NAS ORGANIZAÇÕES - DANILTON CARLOS DA SILVA; JUSSARA GOULART DA SILVA

5. A ROTULAGEM AMBIENTAL COMO INSTRUMENTO DE EFETIVAÇÃO DO DESENVOLVIMENTO SUSTENTÁVEL - MARCEL CARLOS LOPES FÉLIX. 


\title{
COMO OS UNIVERSITÁRIOS DO CURSO DE DIREITO E ADMINISTRAÇÃO DA UEMG, UNIDADE FRUTAL, LIDAM COM SUAS FINANÇAS PESSOAIS?
}

\author{
SILVA, Mônica Queiroz da ${ }^{107}$
}

\begin{abstract}
RESUMO: Este artigo descreve e analisa a importância do conhecimento de conteúdos voltados à Educação Financeira no ensino superior por meio de revisão literária e estudo de campo, objetivando analisar se os universitários são educados financeiramente e 0 papel da Universidade no sentido de fomentar e apoiar neste conhecimento, visando contribuir para a formação de jovens universitários que vivem numa sociedade capitalista com práticas de consumo exagerado e ampla facilitação do crédito. Foi realizada uma pesquisa de campo por amostragem desenvolvida junto aos alunos universitários dos cursos de Direito e Administração (ingressantes e concluintes) da UEMG - Unidade Frutal para analisar o conhecimento financeiro e como estes estudantes gerem suas finanças pessoais. Os resultados da pesquisa mostraram que boa parte dos pesquisados possuem dívidas, têm pouco conhecimento financeiro e lidam com suas finanças pessoais utilizando-se de serviços financeiros em que incidem altos juros. Com base nesses dados e no fato da educação financeira não ser oferecida na UEMG - Frutal propõe-se, ao final, a criação de alternativas para aprimorar o domínio de conteúdo de Educação Financeira pela comunidade universitária. A Educação Financeira contribui para a formação de cidadãos conscientes, capazes de tomar decisões embasadas no conhecimento financeiro e nas demandas com que lidam no dia-a-dia, para que possam ter uma vida digna e menos dependente dos humores do mercado e dos estímulos consumistas da sociedade capitalista.
\end{abstract}

PALAVRAS-CHAVE: Educação financeira, Ensino superior, UEMG Unidade Frutal.

\section{INTRODUÇÃO}

0 dinheiro é necessário e, mesmo que não o consideremos essencial em nossas vidas, não há como deixá-lo de lado. Se contar que as finanças são parte da nossa vida cotidianamente.

O Brasil foi palco de pelo menos duas décadas de inflação e, devido à instabilidade econômica, os preços aumentavam diariamente. Nesse contexto, as pessoas não tinham condições de planejarem gastos e fazerem planos para poupar. 0 planejamento financeiro pessoal, segundo D'Aquino (2008), por mais sério e bem intencionado que fosse, tinha resultados fragilizados e desanimadores.

\footnotetext{
${ }^{107}$ Mestre em Educação pela Universidade de Uberaba (UNIUBE). Especialista em Auditoria Contábil pelas Faculdades Integradas Soares de Oliveira de Barretos. Graduada em Ciências Contábeis pela Faculdade de Ciências Contábeis de Barretos. Docente na UEMG, Unidade Frutal, desde 2005. Atua como contadora e perita judicial na 1a. Vara de Frutal. Link para o LATTES: http://buscatextual.cnpq.br/buscatextual/visualizacv.do?id=K4218289Y7.
} 
Com a implantação do Plano Real, a partir de 1994, a inflação foi reduzida e aumentou o poder aquisitivo do dinheiro. As pessoas passaram a ter mais noção de valor, referências de preço e a cuidar mais do seu dinheiro. Nesse sentido, Cherobim (2011), afirma que a percepção de valor foi fortalecida tanto no que se refere a guardar quanto a gastar.

D’Aquino (2008) frisa que em um cenário econômico sufocado pela inflação não havia uma educação financeira sólida para a formação dos cidadãos. Com a estabilidade da moeda, surge a possibilidade de planejar, desde o projeto mais simples como, por exemplo, as próximas férias até a aposentadoria.

Nos últimos anos, principalmente a partir de 2008, o Banco Central do Brasil, órgão regulador, cuja missão é assegurar a estabilidade do poder de compra da moeda, visando o desenvolvimento econômico tem adotado medidas para reduzir a inflação e alcançar maior estabilidade econômica:

\begin{abstract}
Esse ambiente econômico estável possibilitou o aumento da oferta de produtos e serviços financeiros, entre eles o crédito, ampliando o poder de consumo de grande parte da população, inclusive daqueles anteriormente excluídos do sistema financeiro. Contudo, para usufruir dos benefícios econômicos que podem ser proporcionados por esses produtos e serviços, é importante que os usuários e clientes do sistema financeiro saibam como utilizá-los adequadamente (BANCO CENTRAL DO BRASIL, p. 08, 2013).
\end{abstract}

0 uso de cartão de crédito, empréstimo consignado, cheque especial, financiamento de imóveis, veículos e eletrodomésticos, redução da taxa de juros e prolongamento das parcelas são exemplos de produtos e serviços disponiveis, de forma fácil, para a população, com o intuito de expandir o crédito e o consumo.

A facilidade para obtenção de crédito e 0 incentivo ao consumo têm levado as pessoas ao descontrole financeiro e ao endividamento, ocasionando a inadimplência, um sinal de que os gastos estão maiores que os ganhos auferidos. Essa desproporção leva ao não cumprimento das obrigações na data do vencimento das contas.

Segundo o Indicador de Inadimplência do Consumidor divulgado pela "Serasa Experian" (2015), a inadimplência da pessoa física encerrou o ano de 2014, com um crescimento de 6,3\% em comparação com o ano anterior.

$O$ indicador apontou que no primeiro semestre de 2015 houve um crescimento na inadimplência de $16,4 \%$ na comparação com o mesmo período do ano anterior, sendo a maior alta nesta relação desde 2012 segundo a "Serasa Experian" (2015).

0 que pode levar o indivíduo ao endividamento não se justifica apenas pela má gestão de sua vida financeira ou pela escassez de dinheiro, uma vez que 0 aspecto afetivo também influencia no momento de gastos e consumo desacelerado (SILVA, 2015).

Tolotti (2007) esclarece que, quando as escolhas financeiras são regidas pelas motivações afetivas, as decisões financeiras são tomadas de forma errônea, impulsiva, sobretudo quando a compra de um produto tem um determinado significado. Da compra de um sapato a de um iate, o status, o poder, a autoestima e a imagem que se deseja passar para 0 outro são alguns dos motivos conscientes ou inconscientes que determinam as escolhas do individuo no seu dia-a-dia.

Quando se trata de um ambiente em que o consumo é fruto da emoção, perdurando o desejo e o impulso, o conhecimento financeiro, por si só, poderá não ser 
suficiente para gerir os gastos. Martins enfatiza que "a necessidade de ostentar e a vaidade excessiva são emoções que conduzem a pessoa a fazer gastos exagerados, na hora errada, de maneira impensada e abusiva, transformando-a numa máquina de destruir dinheiro" (2004, p.52).

Atualmente, a prática mercadológica típica da sociedade capitalista moderna ou sociedade de consumo é, segundo Sandroni (2010), levar o consumidor, mediante a máquina publicitária e todas as técnicas de marketing, a sentir necessidade de consumir aquilo que é produzido.

Tobias e Cerveny (2012) afirmam que o marketing surge para criar demandas, necessidades e desejos no estilo de vida do consumidor, motivando-o a comprar.

Atualmente, a propaganda tem sido um forte veículo de comunicação utilizado para efetuar a venda, por tornar, cada vez mais acessível, o produto para todos os públicos consumidores, sejam crianças, jovens, adultos e idosos.

Os comerciais, veiculados nos meios de comunicação, divulgam os produtos e os serviços oferecidos pelas empresas, visando à maximização de riquezas, de lucros e 0 atendimento das necessidades de vendas. A mídia, por sua vez, através do marketing, transforma as mensagens em valores e princípios a serem seguidos e, portanto, muitas pessoas passam a viver de aparência, assumindo uma posição que não podem sustentar e acabam entrando no circuito do endividamento, tal como afirma Tolotti (2007).

Pesquisas mostram que a falta de controle financeiro é um dos fatores de endividamento e que, consequentemente, 0 orçamento familiar e 0 ato de poupar são formas de lidar com o dinheiro e, provavelmente, não fazem parte da vida dos consumidores endividados, ou são feitos de maneira ineficaz e improdutiva. $\mathrm{Na}$ concepção de Tobias e Cerveny (2012), o fato de haver endividamento pode estar relacionado, também, ao consumismo.

Tolotti (2007) defende que aumentando o conhecimento na área financeira, a capacidade de crítica frente ao consumo interfere nas decisões e assim maiores serão as possibilidades de rompimento com a cultura do endividamento.

Para Silva (2015), a educação financeira é um processo que contempla três bases formativas: conhecimento financeiro, disciplina e conscientização, as quais norteiam e assessoram na prática cotidiana, que por sua vez, influencia em todo o ciclo da vida, dando suporte no comportamento e atitude de cada pessoa, fazendo com que ela reflita, critique e escolha a melhor opção no gerenciamento de suas finanças, seja no consumo, no investimento ou em uma situação de endividamento.

As finanças estão presentes na vida das pessoas e 0 ato de educá-las em relação à sua vida financeira consiste em instruí-las, demonstrando, por exemplo, através de fatos cotidianos como a teoria pode ser aplicada na prática. $O$ reconhecimento e a decisão caberão a cada indivíduo mediante o conhecimento adquirido (SILVA, 2015).

Os educadores financeiros, pesquisadores, governantes, organizações internacionais, nos últimos anos, têm demonstrado preocupação com a educação financeira e estão desenvolvendo diversas atividades no sentido de propagar o tema, de conscientizar e orientar a população.

A Organização para Cooperação do Desenvolvimento Econômico (OCDE) e o Banco Central do Brasil (BCB) são exemplos de órgãos que vêm desenvolvendo iniciativas e criando políticas para levar a educação financeira às escolas e à comunidade, visando preparar os cidadãos para gerir as próprias finanças. 
O tema Educação Financeira já se tornou política pública através da Estratégica Nacional de Educação Financeira (ENEF). Após um projeto piloto desenvolvido em 2010 e 2011, foi elaborado o projeto pedagógico em parceria com a Secretaria de Educação Básica do Ministério da Educação (MEC), União Nacional dos Dirigentes Municipais de Educação (UNDIME) e Conselho Nacional de Secretários da Educação (CONSED), para ser inserido na grade curricular das escolas públicas brasileiras, de Ensino Médio, desde 0 ano passado.

Constata-se, portanto, que a implantação do tema na rede pública de educação já é realidade no país, mas não está contemplada a inserção no ensino superior.

$O$ objetivo deste trabalho foi analisar e descrever como os alunos ingressantes e concluintes dos cursos de Administração e Direito da UEMG da Unidade Frutal gerem suas finanças pessoais, o nível de conhecimento financeiro que têm, bem como identificar e descrever a importância do conhecimento de conteúdos de Educação Financeira no ensino superior e propor alternativas para inserção do tema na universidade.

Para analisar o nível de conhecimento financeiro e de gestão das finanças pessoais dos alunos, o trabalho utilizou uma pesquisa de campo, cujos dados foram coletados por meio de um questionário aplicado aos universitários da UEMG - Frutal, ingressantes e concluintes, dos cursos de Administração e Direito.

Almejando um melhor desenvolvimento do trabalho, a pesquisa foi dividida em duas etapas.

Na primeira foi efetuada a revisão literária abrangendo livros, dissertações, teses, artigos e sites especializados sobre educação financeira, a fim de colher as informações teóricas essenciais ao desenvolvimento do tema, bem como para apresentar sugestões de como a educação financeira poderá contribuir na formação dos alunos universitários, independentemente do curso.

Na segunda etapa, foi feita uma pesquisa de campo através de um levantamento de dados efetuado por intermédio da aplicação de um questionário, com 177 universitários da UEMG - Frutal, ingressantes e concluintes dos cursos de Administração e Direito. A pesquisa foi aplicada de forma voluntária e sem identificação do pesquisado.

O questionário foi elaborado com questões semiestruturadas, versando sobre três aspectos: informações socioeconômicas, atitude e comportamento em relação às finanças pessoais e o conhecimento sobre educação financeira, com apresentação de um estudo quali-quantitativo.

A escolha dos cursos de Direito e de Administração, como objeto de estudo, se deu em virtude de ambos serem da mesma área de conhecimento, ou seja, Ciências Sociais Aplicadas e as disciplinas relativas às finanças como, por exemplo, Matemática Financeira, Administração Financeira, Mercado Financeiro e correlatas não comporem a matriz curricular do curso de Direito, por não fazerem parte da formação profissional. Ressalta-se, também, o fato de conteúdos voltados à Educação Financeira não serem aplicados em ambos os cursos.

A pesquisa quantitativa desenvolvida neste trabalho visou quantificar os dados coletados, por meio dos questionários, através de uma análise estatística.

Para consolidação dos procedimentos, a pesquisa teve caráter qualitativo para interpretar o resultado encontrado na pesquisa quantitativa, visando a compreensão da influência das variáveis contidas no questionário. 
Os dados coletados foram tabulados e expostos em forma de tabelas e os resultados, nelas expressos, analisados a luz dos pressupostos teóricos oriundos da pesquisa bibliográfica.

O problema desta pesquisa tem em vista o cenário econômico brasileiro que, nos últimos anos, tem se caracterizado por um elevado consumo de bens variados por parte da população. 0 governo tem usado de diversos mecanismos para fomentar a economia e consumo e, por meio deles, oferece subsídios para o aumento dos gastos das famílias, tais como: facilitação de crédito, isenção de tributos de alguns produtos como carros e eletrodomésticos, eletrônicos e motos.

$O$ endividamento familiar e os juros altos que são praticados no Brasil têm gerado um desequilíbrio financeiro na vida das pessoas, ocasionando o aumento da inadimplência. Boa parte da população não está preparada para administrar suas finanças e necessita de apoio e orientação no que tange à administração de ganhos e gastos, o que não é oferecido no ensino básico brasileiro.

Por estas razões, o trabalho pretendeu responder se encontraríamos nos cursos de Direito e Administração da UEMG - Frutal um número considerável de estudantes universitários endividados, que gastam mais do que ganham. Sem conhecimento financeiro suficiente para equilibrar a situação financeira, eles valendo-se de recursos disponiveis no mercado financeiro, cujos juros são altos juros; não tendo planejamento financeiro; propensos ao consumo e que boa parte não possui uma reserva financeira.

\section{CONTEXTO HISTÓRICO DO DINHEIRO E DA MOEDA}

Real, Dólar, Libra Esterlina, Euro, Renminbi chinesa, Rúpia indiana. Dinheiro, dinheiro e mais dinheiro! Ouro? Prata? Não108. São papeis sujos, rasgados, rabiscados, às vezes, novos e rangentes ou pequenos discos de metais. Porém, com o passar do tempo surgiram novas formas de dinheiro como cheques, cartão de crédito e de débito (dinheiro de plástico) e o dinheiro eletrônico ou moeda digital (usado para pagamento de transações no comércio eletrônico).

A palavra dinheiro vem do latim denarius, nome dado a uma antiga moeda romana. Essa palavra foi usada para denominar uma moeda de prata e cobre que circulava em Castilha, na Espanha e depois foi utilizada para designar todas as moedas e todo o tipo de dinheiro, tal como mostra informação disponibilizada pelo Banco Central do Brasil (2002).

Já, a palavra "moeda", conforme Tobias e Cerveny (2012), é originária do latim, do templo da deusa "Juno Moneta", local em que eram confeccionadas as moedas romanas.

Sandroni (2010), lembra que em inglês, o termo money conservou o sentido específico de "moeda" até o final do século XX, quando, então, foi generalizado o seu significado como dinheiro.

Mas, qual é a diferença entre moeda e dinheiro? Moeda é o meio para concretização das transações monetárias. Com ela, é possível saldar dívidas, e 0 portador deste ativo pode adquirir bens e serviços, uma vez que ele é de aceitação geral pela sociedade.

\footnotetext{
${ }^{108}$ Adaptado do livro A origem do dinheiro, de Jozsef Robert (1989).
} 
Já, dinheiro, é a forma de constituição do ativo, ou seja, pode ser formado por notas (geralmente em forma de papel), por moedas (peça de metal), por cartões (plástico) e digital permitidos para circulação.

Com a apresentação do dinheiro, em forma de moeda, pode-se adquirir um bem ou serviço de acordo com as necessidades humanas. A moeda, nesse sentido, é um objeto aceito pela sociedade e tem o poder de quitação.

Robert (1989) destaca que no início da sociedade humana, no decorrer de dezenas de milhares de anos, a noção de dinheiro era absolutamente desconhecida, pois os homens da sociedade primitiva viviam e se desenvolviam sem ter ciência tanto do termo quanto de seu significado.

Os grupos humanos primitivos, conforme Lopes e Rossetti (1993), não se utilizavam de quaisquer formas de moeda, porque além de serem nômades, sobreviviam sob padrões bastante simples de atividade econômica. As atividades eram realizadas com trocas diretas em espécie, denominadas escambo, também conhecida como economia de trocas.

Com o passar do tempo, surgem produtos que passam a ser intermediadores de trocas, mesmo que de forma primitiva:

Para permitir o desenvolvimento das trocas, agora fundamentais para o
progresso social, o escambo foi dando lugar, gradativamente, a processos
diretos de pagamento. A generalizada aceitação de determinados produtos,
recebidos em pagamento das transações econômicas que dia a dia se tornam
mais intensas, configurando a origem da moeda. Eleitos como intermediários
de trocas, esses produtos, mesmo que não sejam no momento, úteis ou
desejados pelos que os recebem, são aceitos sem grandes restrições, porque
todos sabem que todos os aceitam (LOPES E ROSSETTI, 1993, p. 17).

A origem da moeda surge para desenvolver o sistema de trocas, dando um importante passo para o desenvolvimento da economia, embora de forma rústica.

Para Gremaud, Vasconcelos e Toneto Junior (2005), o surgimento da moeda decorre do progresso econômico, uma vez que, com a especialização dos indivíduos em produções isoladas eles não eram capazes, por si só, de atender ao conjunto de suas necessidades e, portanto recorriam aos demais agentes para obtenção de troca, visando atender suas vontades.

Conforme explicitado por Lopes e Rosseti (1993), as primeiras moedas foram mercadorias. Estas deveriam ser suficientemente raras (para que tivessem valor) e deveriam atender a uma necessidade comum e geral. Desta forma, os primeiros tipos de moeda tinham, essencialmente, valor de uso, e, sendo este comum e geral, passa a ter, concomitantemente, valor de troca.

As moedas-mercadorias chegaram até a Idade Moderna e foram progressivamente perdendo espaço nas negociações, surgindo então os metais.

Com a inserção da moeda, como intermediária de troca, as necessidades dos indivíduos passam a ser livres, devido à dispensa da dupla coincidência de desejos e interesses. 0 dono de um comércio pode vender determinada mercadoria, guardar a moeda e utilizar este dinheiro num outro dia, quando, realmente, surgir a necessidade de usá-lo.

Cabe assinalar que segundo Lopes e Rossetti (1993), a utilização de metais como moeda viabilizou o processo de cunhagem, e os governantes certificavam o peso e garantiam a circulação, além de usarem a moeda cunhada como veículo de propaganda, 
pela cunhagem, da própria efígie. 0 processo de cunhagem da moeda possibilitou a cobrança de tributos.

Lopes e Rossetti (1993) relatam que as funções básicas da moeda, tais como reserva de valor e instrumento de troca, ficaram comprometidas e estes metais não nobres foram substituídos por ouro, prata e outros metais preciosos.

Os metais preciosos assumiram a função de moeda por diversas razões: limitação à natureza, durabilidade e resistência, divisíveis em peso etc., como afirmam Vasconcellos e Garcia (2005).

Lopes e Rossetti (1993) enfatizam que a substituição dos metais não nobres pelo ouro e pela prata foi motivada por alguns fatores adicionais tais como:

Os metais preciosos sempre foram muito procurados e desejados como meios de expressão de poder e riqueza.

O ouro e a prata, devido à escassez, se mantinham relativamente estável ao longo do tempo.

Com o crescimento dos negócios, a produção de metais passou a ser escassa.

Mas vários descobrimentos, dentre eles, a América no século XVI, alavancaram 0 estoque de ouro e prata, e a produção e os negócios não pararam de crescer.

A moeda passa a ser um instrumento básico no funcionamento da economia, atuando nas negociações. Para Vasconcellos e Garcia, o conceito de moeda pode ser definido como "um instrumento ou objeto aceito pela coletividade para intermediar as transações econômicas, para pagamento de bens e serviços" (2005, p. 139).

A função primordial da moeda é a de servir como intermediária de trocas, permitindo assim a superação da economia do escambo dando passagem para a economia monetária.

A função da moeda é relevante à medida que facilita o crédito e a distribuição de diferenciadas formas de adiantamento, no tempo, viabilizando a forma como se realizam os processos de investimento, de produção e consumo, bem como promove 0 surgimento de pagamentos diferidos, ao longo das sucessivas etapas de geração dos bens e serviços destinados à satisfação das necessidades humanas segundo afirmam Lopes e Rosseti (1993).

Historicamente, a moeda evoluiu da chamada moeda-mercadoria, passando pela moeda metálica e pela moeda papel até chegar ao papel-moeda.

A moeda papel, conforme Gremaud, Vasconcelos e Toneto Junior (2005), corresponde a uma nota de papel que explicita determinado valor de ouro, isto é, possui lastro em determinada mercadoria.

O uso generalizado da moeda papel abriu campo para o desenvolvimento de uma nova modalidade de moeda, não integralmente lastreada, baseado na experiência da custódia.

A partir do século XVII, surgem os bancos comerciais privados, que começaram a emitir notas ou recibos bancários, os quais passaram a circular como moeda, dando origem ao papel-moeda. Alguns desses bancos, segundo Vasconcellos e Garcia (2005) receberam o privilégio de monopolizar a emissão das notas bancárias. Este monopólio deu origem aos bancos centrais e, posteriormente, o Estado passou a monopolizar a emissão do papel moeda.

Paralelamente à moeda fiduciária, surgiu a moeda bancária, também chamada de escritural ou de invisível. A moeda bancária surge com a abertura de uma conta corrente, 
com depósitos em dinheiro ou cheques e seu resgate ocorre por meio de ordem de pagamento ou mediante emissão de cheque (moeda escritural).

A definição de cheque vem a ser a de uma ordem de pagamento a vista, que envolve emitente, isto é, individuo titular de uma conta corrente e o beneficiário, ou seja, aquele que recebe o pagamento. Com o tempo, o cheque passou a ser usado como forma de crédito e recebeu a denominação de pré-datado. Nesta negociação o emitente não tem dinheiro disponível na conta corrente de forma imediata e negocia, com 0 beneficiário, a postergação do pagamento.

Resumidamente, Vasconcellos e Garcia (2005) enumeram três tipos de moeda: "Moedas metálicas: emitidas pelo Banco Central, visando facilitar operações de pequeno valor; Papel moeda: também emitida pelo Banco Central e representa parcela significativa de quantidade de dinheiro em poder do público; Moeda escritural ou bancária: representada pelos depósitos a vista efetuados em conta corrente".

O banco, ou seja, o agente financeiro, ao emitir moeda e efetuar um empréstimo ao cidadão gera um débito. Uma vez que o débito foi gerado, o tomador do empréstimo devolve ao banco o valor acrescido de juros. Assim, o banco não recolhe nada e a operação é finalizada. Neste processo, o emitente da moeda não pode utilizá-la e o tomador, ao usá-la em forma de empréstimo, não pode emiti-la.

Com o avanço tecnológico e a globalização surgem novas modalidades de efetuar pagamentos de forma eletrônica que são os cartões de crédito e débito, definidos, popularmente, como o dinheiro de plástico.

O cartão de crédito, por sua vez, é um instrumento que disponibiliza ao seu titular um limite de crédito para aquisição de bens e serviços, e a quitação da dívida pode ser a vista, na data do vencimento da fatura, ou através de um limite de crédito disponibilizado pela instituição financeira, conforme Assaf Neto (2006).

Monteiro (1998) considera que um avanço, oriundo da tecnologia digital, foi 0 surgimento do dinheiro eletrônico (e-money), completamente virtual, criado e usado exclusivamente no espaço virtual, possibilitando, assim, o comércio eletrônico. Ele pode ser armazenado em um chip, e este colocado num cartão de plástico semelhante aos cartões de crédito tradicionais, chamados de smart cards ou cartões inteligentes.

A forma de usar o dinheiro, ao longo dos anos, sofreu muitas transformações, tendo em vista as mudanças tecnológicas, econômicas e sociais que influenciam diretamente na vida das pessoas, inclusive na questão financeira.

A circulação do dinheiro é feita por meio dos agentes econômicos, sendo governo, empresa e famílias. Wonnacott e Wonnacott (2004) demonstram a representação do fluxo de bens, de serviços, de recursos e de pagamentos monetários de forma simplificada:

- As unidades familiares fornecem trabalho e outros recursos de produção que formam os insumos do setor empresarial para o desenvolvimento do negócio e, em contrapartida, as empresas remuneram as unidades familiares por meio de salários, ordenados, juros, aluguéis e dividendos;

- De posse das remunerações, as unidades familiares adquirem bens e serviços para satisfazer suas necessidades, sendo que estes bens e serviços são fornecidos pelas empresas; 
- As empresas utilizam a receita de vendas e serviços para pagar os salários, os ordenados e os demais custos, enquanto as famílias usam a renda para seu consumo;

- O governo recebe das empresas, das unidades familiares e dos intermediários financeiros 109, os impostos diretos e indiretos;

Os excedentes da renda, sob a forma de poupança das unidades familiares, empresas e do governo, são enviados ao sistema financeiro que intermedeia os recursos, destinando-os ao financiamento do consumo das famílias, do capital de giro das empresas e da formação de capital das empresas e governo.

\subsection{Trajetória evolutiva da moeda no Brasil}

A evolução do sistema monetário no Brasil segue uma ordem semelhante ao observado na maior parte das economias ocidentais e o primeiro dinheiro a circular, no país, foi a moeda-mercadoria.

No Brasil, durante muito tempo, o comércio foi feito por meio de troca de mercadorias, mesmo após a introdução da moeda de metal. Mas a primeira "moeda" brasileira de fato foi o açúcar, em 1614. 0 fumo, o pano de algodão e a madeira (paubrasil) também eram muito utilizados com essa função, segundo dados do Banco Central do Brasil (2004).

Com a intensificação das viagens à terra recém-descoberta e a implantação de núcleos de colonização começaram a circular as primeiras moedas no Brasil, as quais foram trazidas pelos portugueses, pelos invasores e pelos piratas. A partir de 1580, com a união das coroas de Portugal e Espanha, moedas de prata espanholas passaram a circular, no Brasil, em grande quantidade.

Sandroni (2010) registra que durante o periodo colonial (1500-1822) circularam vários tipos de moeda que chegaram com a colonização portuguesa, sendo que algumas foram cunhadas em Portugal e outras já em território brasileiro, pois naquele período houve a criação das Casas de Fundição e das Casas da Moeda.

A primeira tentativa de circulação110 de moedas restritas ao nosso território ocorreu em 1642, com a aplicação de carimbos nas moedas portuguesas e hispanoamericanas que aqui circulavam. Foi, entretanto, no território ocupado pelos invasores holandeses que se cunhou a primeira moeda em terras brasileiras - 0 florim de ouro -, acompanhado pelo soldo, moeda de prata, também cunhada pelo invasor batavo, em 1654. Ambas traziam a marca da Companhia de Comércio das Índias Ocidentais e a palavra Brasil aparecia no reverso dos florins.

A partir de 1694, com a criação da Casa da Moeda da Bahia, teve início o processo de cunhagem de moedas brasileiras que, posteriormente, foram produzidas em outros centros da Colônia, como Rio de Janeiro em 1698, segundo afirma Sandroni (2010).

\footnotetext{
${ }^{109}$ São instituições que captam recursos dos poupadores (ofertantes de recursos) para emprestá-los aos investidores que são demandantes de recursos (GREMAUD; VASCONCELOS; TONETO JUNIOR, 2005).

${ }^{110}$ Banco Central do Brasil (2004).
} 
Vasconcellos e Garcia (2005) mencionam que em 1808, quando da chegada de D. João $\mathrm{VI}$, todo o meio circulante era constituído de peças metálicas, mas já havia 0 primeiro vestígio de papel moeda, naquela época, chamado de bilhete de permuta (recibos de recolhimentos metálicos na Casa da Moeda).

Devido à queda na produção de ouro e ao crescimento dos gastos com a implantação da administração no Rio de Janeiro, a quantidade de moedas em circulação tornou-se insuficiente. Assim, em 1808, D. João VI criou o Banco do Brasil, o primeiro banco da América do Sul e o quarto do mundo. Em 1810, foram emitidos os primeiros bilhetes do Banco, precursores das cédulas atuais, segundo informações do Banco Central do Brasil, (2004).

A partir da independência, em 1822, o meio circulante brasileiro consistiu de moedas metálicas e de cédulas de papel moeda. Com a República, segundo Lago (2004), a cunhagem de moedas de ouro e prata foi se tornando cada vez mais limitada e as cédulas passaram a representar boa parte do meio circulante de maior valor, enquanto moedas de níquel e de bronze, e depois de bronze-alumínio, alumínio e, finalmente, aço, serviam para pequenas transações.

Mesmo com uso de cheques, cartões de crédito e de débito e das cédulas de papel moeda, a moeda metálica continua a servir de troco e para o pagamento de negociações de pequeno valor.

As cédulas e moedas brasileiras, de acordo com o Banco Central do Brasil (s.d.), têm a seguinte cronologia:

- Anterior a 1942 - réis;

- 1942 - cruzeiro;

- 1970 - cruzeiro novo;

- 1986 - cruzado;

- 1989 - cruzado novo;

- 1990 - cruzeiro;

- 1993 - cruzeiro real;

- 1994 - real (até o dia de hoje).

Em 1994, por meio do Plano Real, foi criada a moeda Real $(\mathrm{R} \$)$, no sentido de estabilizar a economia, combater a inflação e aumentar o poder aquisitivo do dinheiro. Porém, o problema da inflação no Brasil é antigo, pois D. Pedro cunhou moeda, em 1822, visando à independência, mas tornou o Brasil livre e endividado. Anteriormente à implantação do Plano Real, havia uma hiperinflação de $2.477,15 \%$. Vinte anos depois, a inflação fechou o ano de 2014 em 6,41\%. Constata-se, portanto, que somente em 1994, com a implantação da moeda Real houve sucesso na política anti-inflacionária.

Em tempos de inflação no Brasil, quanto ao gastar, o processo era rápido, lembra Cherobim (2011). Assim que recebiam seus salários, pensões, aposentadorias, aluguéis, enfim seus rendimentos, as pessoas se dirigiam, rapidamente, para os supermercados e para as lojas para comprar os bens que lhes eram necessários. A pressa se justificava em decorrência do aumento, praticamente diário, nos preços dos produtos, assim, a compra imediata era melhor forma de se economizar.

Cherobim (2011) relata que, com a contenção da inflação os preços pararam de subir, as pessoas e as famílias começaram a ter noção de valor, de preço e, por 
conseguinte, passaram a cuidar melhor de seu dinheiro. Faz-se necessário ressaltar que, não é que os preços de bens e de serviços deixaram de subir, estes, agora, sobem dentro de parâmetros razoáveis, controláveis. Sendo assim, com mais controle, é possivel administrar melhor o dinheiro.

De acordo com Silva (2015), o dinheiro, nas suas diversas formas, surgiu para facilitar a vida da população, no que diz respeito à produção, à compra, à venda e aos diversos meios de pagamento e de recebimento, de uma forma cíclica. No principio, as habitantes da Terra foram percebendo a necessidade e criando alternativas práticas para efetuarem a troca de mercadorias, com intuito de atender suas necessidades e alcançar seus desejos. Aos poucos, foram criando formas facilitadoras que pudessem, cada vez mais, atender, de modo eficaz, as necessidades da humanidade. Além do uso no comércio, surge o uso de dinheiro pelas instituições financeiras (bancos) que começaram a obter lucro tanto com a guarda quanto com o empréstimo deste mesmo dinheiro. Assim, o uso de dinheiro e de moeda foi disseminado entre os povos e, no século XXI, vive-se a dependência destas ferramentas para sobrevivência da humanidade.

\section{RELEVÂNCIA DA EDUCAÇÃO FINANCEIRA}

D'Aquino alerta que "desde que surgiu o dinheiro, surgiu a necessidade de se pensar sobre ele" (2008, p. 4). Na Grécia antiga, por exemplo, conselhos sobre o melhor uso de finanças já eram escritos e discutidos.

O filósofo Aristóteles discorreu sobre a questão dos gastos excessivos, problema que perdura até os dias atuais:

A pessoa que tende para o excesso e é vulgar excede-se, como já dissemos, por gastar além do que seria razoável. Agindo assim, ela gasta demais e demonstra um exibicionismo de mau gosto em ocasiões pouco importantes [...]. E tudo isso ela faz não por motivo nobilitante, mas para exibir sua riqueza, e por pensar que é admirada em consequência dessa maneira da agir, ademais, onde deve gastar muito ela gasta pouco, e onde deve gastar pouco gasta muito (ARISTÓTELES, 1996, p. 180).

Conforme descrito por D'Aquino (2008), a partir do século XIX, nos Estados Unidos houve a construção das ferrovias rumo ao Oeste Americano, fato que sustentou e concentrou dinheiro e poder nas mãos de poucos. Com esse padrão social, as pessoas se distinguiam umas das outras, de acordo com o modo de produção, grau de instrução, número de filhos, tipo de moradia, alimentação, vestimentas etc. Com o advento dos bilionários norte-americanos, a extravagância e a ostentação passaram a ser admiradas nas pessoas que demonstravam a gastança, o consumo. Com a crise de 1929 (Grande Depressão), com a recessão americana, o esbanjamento consumista veio a reduzir. A partir da década de 80 , na segunda metade do século XX, surgem novos bilionários provenientes de vários segmentos tais como: mercado de eletrônicos, software, telecomunicações, entretenimento. Independentemente da origem de tanto dinheiro, os hábitos, os costumes e as excentricidades que evidenciam a ostentação do dinheiro ressurgiram de forma mais intensa, se fazendo notar não só nos Estados Unidos ou no Brasil, mas em todo o mundo. 
Autoridades financeiras e educativas, em diversos países, segundo Silva (2015), iniciaram trabalhos sobre educação financeira, voltados ao uso consciente do dinheiro, ao preparo dos consumidores para usufruírem, de forma moderada, os produtos financeiros, visando o equilíbrio do orçamento doméstico.

$O$ processo de disseminação da Educação Financeira vem se desenvolvendo em muitos países, sob a orientação da Organização para a Cooperação e Desenvolvimento Econômico (OCDE) 111.

A Organização para a Cooperação e Desenvolvimento Econômico (OCDE) percebendo a necessidade de haver o desenvolvimento da poupança previdenciária e do melhor entendimento dos indivíduos sobre os produtos financeiros, pelo menos dos princípios básicos, criou o Financial Education Project (Projeto de Educação Financeira) para estudar a Educação Financeira e propor programas de Educação Financeira nos países membros e também em países não membros, como, por exemplo, o Brasil.

Segundo OCDE (2005), educação financeira é o processo mediante 0 qual os indivíduos e as sociedades melhoram a sua compreensão em relação aos conceitos e produtos financeiros, de maneira que, com informação, formação e orientação possam desenvolver os valores e as competências necessários para se tornarem mais conscientes das oportunidades e riscos nelas envolvidos. Munidos dessas informações, os indivíduos podem fazer escolhas, sabem onde procurar ajuda e podem adotar outras ações que melhorem o seu bem-estar. Assim, a educação financeira pode contribuir de modo mais consistente para a formação de indivíduos e sociedades responsáveis, comprometidos com o futuro.

De acordo com a OCDE (2004) a educação financeira se faz necessária para auxiliar os consumidores a orçarem e gerirem a sua renda, a pouparem, a investirem e evitar que eles se tornem vítimas de fraudes. No entanto, sua crescente relevância nos últimos anos vem ocorrendo em decorrência do desenvolvimento dos mercados financeiros, e das mudanças demográficas, econômicas e políticas.

Atendendo sugestão da OCDE, os países, dentre eles, o Brasil, vem desenvolvendo uma Estratégia Nacional de Educação Financeira (ENEF)112 com o escopo de favorecer a promoção do tema no país e criar diretrizes para balizar iniciativas concretas, sejam do Estado, da iniciativa privada ou da sociedade civil. A estratégia torna-se a principal referência para leis, políticas públicas e programas multissetoriais, e contribui para gerar ampla mobilização.

A OCDE (2005) recomenda que a educação financeira seja promovida de forma justa e sem vieses, livres de interesses particulares, focando as prioridades de cada país, de acordo com realidade nacional, e também inserida na escola, o quanto antes.

Até o fim dos anos 1990, o assunto educação financeira concentrava-se nas dicas de investimento dos especialistas em produtos do mercado financeiro, as quais ensinavam como preservar ou multiplicar o dinheiro com aquisição de ações, títulos públicos ou privados, envolvendo um público que já tinha recurso disponível e bastava apenas alocar

\footnotetext{
${ }^{111}$ Organização mundial fundada em 1948 composta atualmente por 34 países membros, que através de seu banco de informação sobre uma ampla gama de tópicos ajuda os governos a promover a prosperidade e lutar contra a pobreza através do crescimento econômico e da estabilidade financeira (OCDE, s.d.).

112 A Estratégia Nacional de Educação Financeira - ENEF - é uma mobilização multissetorial em educação financeira. A estratégia foi instituída como política de Estado de caráter permanente, e suas características principais são a garantia de gratuidade das iniciativas que desenvolve ou apoia e sua imparcialidade comercial (ENEF, s.d.)
} 
em determinados tipos de investimentos. Nesta orientação, segundo Araújo e Calife (2014) não se contemplou o caminho para a organização das finanças que resultasse em economia e, posteriormente, pudesse ser investidor no mercado financeiro.

A recente ascensão econômica de milhões de brasileiros coloca 0 cidadão em contato com novas situações e operações financeiras pouco familiares para muitas pessoas. Somado a isso, o aumento das possibilidades de consumo (VIDA E DINHEIRO, s.d.).

Silva (2015) ressalta que a falta de preparo para usar o crédito, abundantemente lançado no mercado, fez com que as pessoas, tomadas pelo anseio de consumir, extrapolassem 0 orçamento doméstico, acreditando que parcelas a perder de vista, pudessem ser pagas sem nenhum empecilho, pois não supunham que pudesse ocorrer uma intempérie e que o compromisso não poderia ser cumprido em tempo hábil.

Macedo Junior (2010) destaca que o crédito é limitado e após esgotar esse limite, as pessoas terão que devolver o valor emprestado e ainda pagar todos os juros decorrentes dele. A falta de planejamento de finanças adequado é a principal razão de pagamentos de juros, decorrentes, na maioria dos casos, do descontrole de cartões de crédito e de cheques pré-datados. Para cada ganhador de juros no Brasil, existem quatro pessoas trabalhando para pagá-los.

Já a falta de conhecimento de conceitos e de produtos financeiros, por parte da população, dificulta o pleno exercício da cidadania. Um caso comum é 0 desconhecimento de informações básicas sobre o crédito consignado, o que levou muitos cidadãos e, em especial, aposentados e pensionistas do Instituto Nacional de Seguridade Social - INSS - a tomarem empréstimos de instituições financeiras sem a consciência que teriam o desconto em folha de pagamento, segundo Araújo e Souza (2012).

Finalizando, Araújo e Calife (2014) mencionam que com a expansão do crédito, houve um aumento expressivo do consumo e maior bancarização da população, tendo como consequência a inadimplência. 0 último período de pico da inadimplência ocorreu em 2011, devido à falta de pagamento das parcelas de financiamento de veículos, e foi necessária uma parada para o rearranjo de crédito. Neste período, chamado de ressaca de crédito, surge a educação financeira e diversos programas com entidades privadas e públicas, dentre eles, a Estratégica Nacional de Educação Financeira e a Associação de Educação Financeira do Brasil.

A Associação de Educação Financeira do Brasil (AEF) é uma organização sem fins lucrativos criada em 2011, com o objetivo de promover a Educação Financeira no Brasil e dedicada ao desenvolvimento de tecnologias sociais e educacionais. A AEF colabora com a Estratégia Nacional de Educação Financeira (ENEF), coordenando e executando seus projetos.

Para melhorar o nível da educação financeira da população brasileira, o governo brasileiro lançou a Estratégia Nacional de Educação Financeira (ENEF) em 2009, sendo publicamente lançada em agosto de 2011, conforme orientação da OCDE. As metas desta estratégia nacional são: desenvolver habilidades financeiras pessoais e estimular 0 comportamento financeiro responsável entre os brasileiros, melhorando, assim, seu bemestar financeiro.

A ENEF tem a finalidade de promover a educação financeira e previdenciária e contribuir para o fortalecimento da cidadania, da eficiência e solidez do sistema financeiro 
nacional e da tomada de decisões conscientes, por parte dos consumidores. Ela foi instituída como proposta de política de Estado, de caráter permanente.

Silva (2015) salienta que a Educação Financeira aplicada no nível superior pode influenciar na vida financeira dos jovens que vão ingressar no mercado de trabalho. Formando cidadãos críticos, conscientes e sensibilizados, alicerçado no conhecimento, com certeza, estes serão capazes de discernir qual o melhor caminho, qual a melhor forma de gerir suas finanças pessoais, assumindo o controle do seu dinheiro.

Silva (2012) preconiza que quem tem conhecimento, não necessariamente está persuadido a agir no sentido do conhecimento que possui. A sensibilização é fundamental para a mudança do comportamento. Alguém sensibilizado não possui apenas o conhecimento financeiro, mas age em consonância do conhecimento que possui.

O objetivo da educação financeira é de formar cidadãos conscientes, capazes de tomar decisões individualmente e o seu papel é de demonstrar as técnicas, os conhecimentos financeiros, por meio dos quais as pessoas irão decidir, com a plena consciência, o que será melhor para suas vidas, optando, assim, por um caminho considerado como o mais viável nas finanças pessoais (SILVA, 2015).

Tolotti (2007) menciona que a economia, longe de ser um assunto complexo com linguagem inacessível, está presente no cotidiano de cada indivíduo. A ciência econômica estuda os fenômenos sociais relativos à produção, à distribuição e ao consumo de bens e serviços que satisfazem as necessidades humanas.

O cidadão compra e consome bens e serviços, e através do seu trabalho recebe uma remuneração (renda) para atender suas necessidades e desejos. Estas necessidades e desejos, muitas vezes, não são compatíveis com sua renda, então, ele recorre ao sistema financeiro que tem o papel de emprestar dinheiro ou financiar bens com a promessa de pagamento do capital acrescido os juros. Desse modo, o indivíduo passa a ter uma dívida, que se não bem administrada poderá ocasionar a ausência de pagamento.

A falta de educação financeira tem levado boa parte das famílias a se endividarem, a pagarem juros exorbitantes, a perderem o controle do fluxo de caixa, a deixarem de honrar os compromissos acordados e ainda terem seus nomes incluídos no banco de dados de órgãos de serviço de proteção ao crédito.

Atualmente, a prática mercadológica típica da sociedade capitalista moderna ou sociedade de consumo é, segundo Sandroni (2010), levar o consumidor, mediante a máquina publicitária e todas as técnicas de marketing, a sentir necessidade de consumir aquilo que é produzido.

A sociedade de consumo caracteriza-se pela produção e pelo consumo ilimitado de bens duráveis, sobretudo de artigos supérfluos. Tolotti (2007) menciona que o consumismo é criticado por mercantilizar toda a atividade humana, suas necessidades materiais e espirituais.

Atualmente, muitas pessoas estão voltadas em acompanhar lançamentos de roupas, acessórios pessoais, produtos eletrônicos, carros e calçados. 0 imperialismo da moda, da globalização e da internet têm encantando o ser humano, levando-o consumir de forma ilimitada. As empresas estão inovando constantemente seus produtos e serviços e os apresentam através da mídia e da internet, com propagandas audaciosas e 
chamativas. Existe uma corrida frenética, por parte por jovens e adolescentes, para comprar lançamentos e novidades.

O ciclo da vida financeira de um brasileiro, conforme Hoji (2010) possui duas fases: o período de acumulação de patrimônio e o de aposentadoria. Uma pessoa tem prazo de 40 anos para acumular patrimônio e de 20 anos para desfrutar deste mesmo patrimônio. Baseado nos dados dos IBGE, divulgados em 2013, a expectativa de vida média de um brasileiro era de 74,8 anos, isto é, 74 anos, 9 meses e 18 dias, sendo 71,3 anos para homens e 78,5 anos para mulheres.

0 ciclo da vida financeira de um jovem com cerca de 22 anos de idade, embora muitos comecem a trabalhar antes, após a conclusão do ensino superior. Observa-se que as despesas são maiores no início, pois existem os gastos com a constituição da família, casamento, nascimento dos filhos, educação dos filhos, compra de imóvel, continuidade da educação do casal (especialização). Com isto, no início da acumulação do patrimônio, a família provavelmente estará endividada e sem patrimônio. Na meia-idade, ainda ocorrerá gastos com educação dos filhos até que estes concluam o nível superior. Os gastos ainda vão existir durante boa parte da acumulação do patrimônio. Portanto, segundo Hoji (2010) o quanto antes os jovens iniciarem a poupança, mais cedo poderão obter sua independência financeira.

\section{RESULTADOS DA PESQUISA}

Os resultados da pesquisa de campo efetuada Universidade do Estado de Minas Gerais Campus Frutal, junto os alunos ingressantes e concluintes, no ano de 2014 foi explorada através de uma população finita por amostragem num total de 177 entrevistados e foi realizada durante o mês de novembro de 2014.

Na amostra, $62,15 \%$ pertencem ao gênero feminino, 37,85\% equivalem ao gênero masculino, com idades entre 18 a 52 anos. Do total, $37,29 \%$ não trabalham.

No quesito controle de gastos mensais, foi questionado que tipo de ferramenta é utilizado para controlar as despesas, bem como se não há um controle das despesas.

O caderno de anotações é utilizado por parte dos pesquisados, sendo que $30,51 \%$ fazem uso desta ferramenta para anotar seus gastos. A memorização dos gastos chegou a $37,85 \%$, considerado um valor bem expressivo. Já aqueles que anotam apenas as compras de maior valor somam $6,21 \%$ dos alunos. 0 uso de aplicativos e planilha eletrônica é utilizado por $14,69 \%$. Alunos que não tem o hábito de controlar os gastos perfazem um total de $10,73 \%$. Mediante estes resultados, conclui-se que $54,79 \%$ dos entrevistados não conhecem detalhadamente todos os gastos despendidos.

Macedo Junior (2010) afirma que poucos brasileiros têm o hábito de colocar no papel suas receitas e despesas. Em geral, as pessoas, quando solicitadas a dizerem para onde vai o salário, só conseguem lembrar-se de aproximadamente $80 \%$ daquilo que gastam, ou seja, não conseguem discriminar cerca de $20 \%$ de suas despesas. Quando começam a anotar os gastos, costumam reduzi-los em cerca de $12 \%$. Isso acontece porque 0 ato de anotar faz com que a pessoa pense duas vezes antes de gastar. Conclui-se que mais da metade dos universitários podem estar gastando mais devido à falta de anotações das despesas. 
No quesito situação financeira, isto é, confronto entre receitas e despesas, $10,73 \%$ dos pesquisados gastam mais do que ganham, sendo que metade dos universitários gasta igual ao que ganha. A fatia de alunos que gastam menos do que ganham e poupam a diferença chegou a $37,29 \%$.

Martins (2004) orienta que é necessário que se faça um orçamento de fluxo de caixa estimando a renda, definindo metas de resultado e fixando despesas. Quando as receitas e despesas são relacionadas no fluxo de caixa é possível analisar item a item e averiguar gastos que podem estar extrapolando o orçamento, sendo possível, então, estabelecer cortes de forma a melhorar o saldo de caixa.

Quanto aos universitários, cujos ganhos são iguais aos gastos, encontra-se um total de $51,98 \%$ que estão sem sobra de caixa. Cabe ressaltar que essa situação pode ser melhorada, através de um melhor gerenciamento dos gastos e ainda obter uma economia mensal, com elaboração de um fluxo de caixa.

Já, $10,73 \%$ dos entrevistados estão ultrapassando os valores de receitas, menos suas despesas. Neste caso, é provável que estejam recorrendo a outras fontes de recursos ou deixando de pagar algumas despesas. Ao analisar o histórico dos alunos que excedem os gastos em relação aos ganhos auferidos, notou-se que 7,91\% dependem da renda dos pais.

Os universitários que investem somam $45,90 \%$ do total. A poupança é um investimento simples e também o mais utilizado, pois $31,14 \%$ dos alunos afirmam que depositam suas economias em conta poupança. Considerado o investimento mais popular do Brasil com rendimento baixo, não tem limite para aplicação. Não há taxa de administração e sem limite para resgate. Este investimento é isento de IOF (Imposto sobre Operações Financeiras) e IRRF (Imposto de renda retido na fonte).

O percentual de alunos, que corresponde a $3,82 \%$ dos pesquisados, desconhecem outras modalidades de investimento e por isso optam pela poupança.

Alguns optam por emprestar sua reserva para terceiros, perfazendo um total de 2,73\%. Este tipo de investimento, que na sua maioria fornece um retorno razoável, se torna um risco no momento do resgate junto ao terceiro se este não tiver condições financeiras de devolver o dinheiro.

Os investimentos em imóveis, previdência privada, ações e títulos de renda fixa perfazem o total de $4,89 \%$, dos investimentos dos entrevistados.

$\mathrm{Na}$ opção outros investimentos (resposta aberta do questionário) que alcançou 3,27\% dos universitários, foram dadas as seguintes respostas: aquisição de cota de consórcio, gado e título de capitalização. No caso do título de capitalização, estudos mostram que o rendimento dele é sempre zero e ainda há perdas para a inflação.

O consórcio não é investimento. Seu objetivo é para compra financiada e há cobrança de várias taxas (taxa de administração, de adesão e fundo de reserva). Uma aplicação financeira pode ser o melhor caminho.

Obtivemos neste item, a resposta de um 01 aluno que considerou viagem e lazer como investimento. Neste caso, há um erro de interpretação, pois se trata de um gasto e não um investimento.

O percentual de universitários que possuem dívidas atingiu $51,98 \%$. Com a armadilha do crédito rápido, fácil e sem complicação, muitas pessoas acabam se endividando e tomam capital emprestado de instituições financeiras que cobram altos juros para emprestar dinheiro. 
No caso dos jovens, várias empresas oferecem linha de crédito especificamente para os universitários com taxa de isenção de serviços, com limite para uso do cheque especial e cartão de crédito. Desta forma, muitos começam a utilizar estes serviços financeiros e passam a fazer parte do ciclo de dívidas.

Muitos destes jovens assistem aos pais que financiam o carro e casa da família em intermináveis prestações, ou então fazem compras no supermercado com o cartão de crédito. Segundo Cardoso (2007), essa desenvoltura em utilizar a fartura do crédito influencia, e muito, a atitude dos filhos.

Tolotti (2007) enfatiza que o endividamento anda na contramão do investimento. Estando os jovens dominados pela cultura do endividamento, somente se transformarão em bons investidores, se houver empenho social, familiar e educacional intenso.

Outro fator averiguado ao longo da pesquisa foi a modalidade de endividamento. 0 item cartão de crédito aparece em primeiro lugar, representando 33,13\%. Esta forma de obtenção de crédito quando não bem administrada gera uma bola de neve. A fatura do cartão tem a opção de pagamento mínimo, ou seja, não é necessário pagar integralmente 0 valor dela, se 0 indivíduo estiver desprovido de dinheiro no vencimento da mesma. O problema está no custo da postergação de parte da dívida, porque os juros cobrados são os mais altos do país.

Entre os jovens e adolescentes, o uso do "dinheiro de plástico" está cada vez disseminado. Com a facilidade para obtenção do cartão de crédito aliado a segurança e comodidade, muitas pessoas tem se endividado.

Em seguida, constata-se que o crediário é responsável por 22,29\% das dívidas dos pesquisados. Normalmente, o crediário é típico de lojas que vendem eletrônicos, eletrodomésticos, móveis, artigos para vestuário e calçados. Nesta modalidade o devedor assina uma duplicata e recebe um carnê para pagar as parcelas.

Os jovens querem andar na moda e ter tudo que a tecnologia oferece de mais moderno. Quando um produto é considerado caro, as lojas que sempre oferecem o pagamento em várias parcelas, com juros embutidos, muitas vezes, não são nem mesmo questionadas se houve aumento em função do prazo. 0 importante é atender o seu desejo.

Outro item que foi mencionado é o financiamento de bens móveis (carro, moto), 0 que representa $14,46 \%$ das dívidas. Nesta modalidade de crédito, as empresas financiam com longos parcelamentos, podendo chegar até 60 meses dependendo do banco ou financeira. Ao financiar um bem móvel, surgem outros gastos além da parcela do bem financiado acrescido os juros. Gastos tais como impostos, seguros, manutenção e 0 combustível também deverão ser acrescidos no orçamento.

O empréstimo bancário representa $10,84 \%$ das dívidas. Na busca pela satisfação pessoal, muitos jovens recorrem a empréstimos. Nesta modalidade, os jovens podem utilizar este dinheiro para a alimentação, aluguel, transporte, festas, saúde, cursos. Pode ser utilizado também para cobertura de outras dívidas, como a do cartão de crédito, por exemplo.

O financiamento de bem imóvel (casa, terreno) é $5,42 \%$. Com o sonho da casa própria e a busca pela independência, muitos jovens assumem prestações que podem chegar até 30 anos para pagamento. Com o incentivo do governo federal e o lançamento de programas habitacionais como Minha Casa Minha Vida, muitas pessoas assumiram este tipo de dívida. 
As modalidades de crédito, cheque especial, empréstimo pessoal, empréstimo consignado e cheque pré-datado somam $13,85 \%$ das dívidas contraídas pelos universitários.

Os motivos que levaram os jovens a contrair dívidas são diversos. Um dos deles é a facilidade para obtenção de crédito, uma vez que, $23,44 \%$ responderam positivamente a este item. A facilidade de acesso ao crédito deixa os jovens deslumbrados e seduzidos pela possibilidade de não precisar adiar as vontades, eles são alvo fácil da mensagem transmitida pela dupla "consumo e crédito". Esses jovens, segundo Tolotti (2007), nasceram e cresceram absorvidos pela sociedade de consumo.

Cardoso (2007) menciona que na busca pela identificação e aceitação de colegas, os jovens agem impulsivamente comprando itens padronizados para acompanhar o padrão da turma. A manipulação do marketing, com persuasão e sedução utilizadas em larga escala, trabalha com o intuito de interferir nas escolhas dos jovens.

O item falta de planejamento financeiro é o motivo pelo qual $19,53 \%$ dos universitários contraíram dívidas. O planejamento financeiro implica na preparação de um orçamento com as receitas e despesas, com objetivos de curto, médio e longo prazo. Já foi apontando anteriormente, na questão de ferramentas para controle de gastos, que $54,79 \%$ dos entrevistados não conhecem detalhadamente todos os gastos despendidos. Se não anotam integralmente os gastos, não tem como planejar, estabelecer metas e projetar investimentos.

O motivo propensão ao consumo é responsável pelas dívidas de $15,63 \%$ dos pesquisados. Segundo Cardoso (2007) uma pesquisa feita em 24 países dos cinco continentes apontou que os brasileiros são os mais consumistas do mundo. Em muitos casos, a maior dificuldade do jovem está em adiar os desejos e ele acaba comprando mesmo sem ter necessidade.

O motivo aquisição de moto e carro conduziu $17,19 \%$ dos entrevistados o endividamento. Este item pesa no orçamento devido ao alto valor das parcelas além de gastos para manutenção do bem. São bens considerados, pelos jovens, como "sonho de consumo".

Os motivos desemprego, queda na renda, empréstimos efetuados do nome do entrevistado, para amigos e familiares, problemas de saúde e aquisição de imóvel totalizam um percentual de $21,87 \%$.

Os alunos foram questionados sobre a perda da fonte de renda, por quanto tempo eles conseguiriam manter o pagamento dos gastos em dia utilizando apenas as economias (reservas).

O item: não tenho reservas apontou que $40,11 \%$ dos alunos não têm recursos financeiros, caso percam sua fonte de renda inesperadamente. Neste caso, não teriam condições de arcar com os gastos.

Entre aqueles que afirmaram ser possivel se manterem por um período de 02 a 03 meses com a reserva, temos $24,86 \%$ dos jovens. Por apenas 01 mês com a reserva, temos $13,57 \%$ ou seja, 24 alunos. Acima de 04 meses, com a economia reservada para imprevistos, perfazem um total de $21,46 \%$. Segundo especialistas, a reserva de emergência ideal deve ser de 6 a 10 meses de renda, pois ela permita a manutenção do padrão de vida da pessoa. 
Em relação ao conhecimento financeiro, foram elaboradas alternativas, nas quais o pesquisado deveria marcar quais são as afirmativas corretas em relação ao próprio conhecimento financeiro.

As respostas a e b eram as corretas. Os alunos que acertaram a questão "a" correspondem a $23,79 \%$ e a questão "b", $26,90 \%$ dos entrevistados.

0 índice de acerto foi baixo em relação ao total pesquisado. A questão "a" está relacionada às informações econômicas e a questão "b" está ligada à Matemática Financeira.

Visando conhecer os dois cursos no que tange à Educação Financeira, foi feito alguns cruzamento de dados.

Os alunos do curso de Direito, que gastam mais do que ganham, chega a $6,21 \%$. 0 percentual do curso de Administração é um pouco mais baixo, cotando com $4,52 \%$ dos pesquisados.

Os graduandos em Administração que gastam igual ao que ganham, perfaz um total de $22,03 \%$. No curso de Direito, o percentual atinge $29,95 \%$, dos alunos que conseguem gastar igual aos ganhos auferidos. Quanto a gastar menos do que ganha, 0 total de alunos do curso de Administração é de 19,78\% e 17,51\% dos alunos do curso de Direito conseguem equilibrar os gastos e obter uma reserva.

No que tange ao endividamento, os alunos do Direito são menos endividados que os alunos da Administração, uma vez que eles perfazem um total de $22,03 \%$. Já os alunos do curso de Administração são $29,95 \%$ dos pesquisados.

Sem dívidas, os pesquisados que estudam no curso de Direito são $31,64 \%$ enquanto aos estudantes de Administração são apenas 16,38\%.

Dos alunos que não possuem dívidas $90,59 \%$ dependem dos pais sendo um dos motivos pelo não endividamento. Os percentuais por curso e período estão alocados da seguinte forma:

- Curso de Administração ingressantes: 20,78\%;

- Curso de Direito ingressantes: 40,26\%;

- Curso de Administração concluintes: $12,99 \%$.

\section{CONSIDERAÇÕES FINAIS}

Esta pesquisa apresentou o levantamento de dados, efetuado por meio de uma pesquisa de campo, cujo objetivo foi verificar a gestão das finanças pessoais e 0 conhecimento financeiro dos alunos ingressantes e concluintes dos cursos de Administração e Direito da UEMG - Frutal, além da apresentação, a partir de uma breve revisão literária, da relevância da Educação Financeira no processo de formação dos jovens universitários.

A análise dos dados, colhidos na pesquisa de campo, demonstrou que os alunos apresentam um déficit de conhecimento financeiro e que a Universidade pouco tem contribuído para a solução dessa carência.

Outro aspecto importante constatado foi o fato de que ao finalizarem os seus respectivos cursos, os universitários, ao atuarem como profissionais passam auferir 
renda, e muitos deles passam a auferir uma renda maior. Tornam-se independentes e, consequentemente, precisam estar educados financeiramente para poderem exercer a gestão de seus ganhos. A preparação dos universitários, portanto, não pode ser somente para obtenção de êxito nas atividades profissionais, mas também alicerçá-los para obter sucesso nas finanças pessoais.

As leituras demonstraram que um dos hábitos que precisam ser cultivados, pelos cidadãos, é o de poupar parte dos ganhos que não foi consumida. Esta sobra de dinheiro pode ser investida ou guardada para ser utilizada no futuro. A pesquisa deste trabalho apontou que $54,09 \%$ dos jovens pesquisados não poupam, isto é, não possuem nenhuma reserva financeira.

Os dados da pesquisa também mostraram que $95,48 \%$ dos entrevistados estão interessados no tema. Portanto, ficou comprovada a importância da proposta de oferecer à comunidade universitária, através de ações, informações e orientações no que tange à educação financeira, a fim de proporcionar aos alunos, um espaço em que possa se discutir a construção de um pensamento financeiro consistente visando 0 desenvolvimento de comportamentos autônomos e saudáveis.

Ao finalizar a pesquisa, constatou-se que as respostas dadas pelos entrevistados e as informações teóricas foram relevantes e deram embasamento para validar a importância de inserção da Educação Financeira na formação dos jovens.

Nesta perspectiva, a propositura deste trabalho foi promover a introdução do tema de educação financeira no nível superior, através das seguintes alternativas:

a) Inclusão por meio de uma disciplina específica (obrigatória ou eletiva) ou a aplicação dos conteúdos do tema Educação financeira em disciplinas correlatas;

b) Oportunamente, trabalhar o tema em forma de palestras, cursos ou minicursos em eventos como: semana universitária, workshops, seminários e congressos;

c) Incentivar a inclusão de um curso versando sobre o tema em apreço, como atividades extracurriculares ou como atividade complementar.

O estudo em questão não teve por objetivo concluir ou esgotar o assunto tratado, mas apenas contribuir para demonstrar a relevância e necessidade de oferecer a Educação Financeira no ensino superior. Considerando que a graduação é uma fase muito importante na vida do jovem e mediante a cultura do consumismo, na qual a política do marketing tem transformado desejo em necessidade, se não haver um despertar para a gestão das finanças, o futuro de muitos jovens estará comprometido.

A educação financeira como base formativa nos desperta, como educadores, no sentido de educar para a vida, além da sala de aula, pois há que se considerar que o processo formativo do cidadão será de grande valia para a sua vida cotidiana, independente da carreira profissional ou de sua formação básica.

Esta pesquisa não objetivou defender a riqueza ou a obsessão por dinheiro. Visou, apenas, à transferência de conhecimento que, ao ser executado com consciência e disciplina, pode propiciar segurança, tranquilidade e qualidade de vida às pessoas.

A abordagem e a implantação do tema educação financeira no ensino superior não resolverão os problemas encontrados na sociedade no que tange ao consumo e endividamento. Como vivemos num regime capitalista que visa o consumo cada vez maior e tem transformado, com a ajuda do marketing, necessidade em desejo, cabe a 
cada pessoa uma análise minimamente segura no momento de consumir, endividar, poupar e investir.

\section{REFERÊNCIAS}

ASSOCIAÇÃO DE EDUCAÇÃO FINANCEIRA (AEF). Resultados da avaliação de impacto do projeto piloto de educação financeira nas escolas. 2012. Disponível em:

$<$ http://www.aefbrasil.org.br/index.php/resultados-da-avaliacao-de-impacto-do-projeto-pilotode-educacao-financeira-nas-escolas/>. Acesso em 08 dez. 2014.

ARAÚJO, Fabio de Almeida Lopes, SOUZA, Marcos Aguerri Pimenta de Souza. Educação Financeira para Brasil sustentável. 2012. Disponível em:

<http://www.bcb.gov.br/pec/wps/port/td280.pdf >. Acesso em 03 dez. 2014.

ARAÚJO, Fernando Conseza; CALIFE, Flavio Estevez. A história não contada da Educação Financeira no Brasil. 2014. Disponível em: <http://www.boavistaservicos.com.br/wpcontent/uploads/2014/08/A-hist\%C3\%B3ria-n\%C3\%A3o-contada-daeduca\%C3\%A7\%C3\%A3o-financeira-no-Brasil.pdf>. Acesso em 30 nov. 2014.

ARISTÓTELES. Ética a Nicômaco. São Paulo: Nova Cultural, 1996.

BANCO CENTRAL DO BRASIL. Dinheiro no Brasil. 2a . Ed. 2004. Disponível em: <http://www.bcb.gov.br/Pre/PEF/PORT/publicacoes_DinheironoBrasil.pdf >. Acesso em 30 set. 2014.

. “O que é dinheiro?". In: Cadernos BC Série educativa. 2002. Disponível em: <https://www.bcb.gov.br/Pre/educacao/cadernos/dinheiro.pdf.>. Acesso em 31 ago. 2014.

. Cédulas e moedas brasileiras. [s.d.]. Disponível em:

<http://www.bcb.gov.br/htms/museu-espacos/pdrmonet.asp?idpai=CEDMOEBR>. Acesso em 30 set. 2014.

. Mercado de Câmbio. 2014. Disponível em:

<http://www.bcb.gov.br/pre/bc_atende/port/mercCam.asp\#1>. Acesso em 01 out. 2014.

Caderno de Educação Financeira Gestão de Finanças Pessoais (Conteúdo Básico). 2013. Disponível em: <http://www.bcb.gov.br/pre/pef/port/caderno_cidadania_financeira.pdf. Acesso em 24 nov. 2014.

BRASIL. Secretaria Nacional do Consumidor. Departamento de Proteção e Defesa do Consumidor. Consumo sustentável. Brasília: Ministério da Justiça, 2013.

CARDOSO, Marília. Você sabe lidar com o seu dinheiro? São Paulo: Artemeios, 2007.

CHEROBIM. Ana Paula Mussi Szabo; ESPEJO. Márcia Maria dos Santos Bortolocci. Organizadoras. Finanças Pessoais: conhecer para enriquecer! 2a . Ed. São Paulo: Atlas, 2011.

CONFEDERAÇÃO NACIONAL DO COMÉRCIO DE BENS, SERVIÇOS E TURISMO (CNC). Perfil do endividamento das famílias brasileiras em 2014. Disponível em: 
<http://www.cnc.org.br/central-do-conhecimento/pesquisas/economia/perfil-do-endividamentodas-familias-brasileiras-em-2014>. Acesso em 22 jan. 2015.

\section{. Pesquisa Nacional de Endividamento e Inadimplência do Consumidor}

(Peic) - agosto 2014. Disponível em: <http://www.cnc.org.br/central-do-

conhecimento/pesquisas/pesquisa-nacional-de-endividamento-e-inadimplencia-do-consumido38>. Acesso em $06 \mathrm{dez} 2014$.

D’AQUINO, Cássia. Educação Financeira: como educar seus filhos. Rio de Janeiro: Elsevier, 2008.

EDUCACIONAL. O dinheiro no Brasil. [s.d.] Disponível em:

<http://www.educacional.com.br/reportagens/dinheiro/brasil.asp\#>. Acesso em 27 nov. 2014.

ENEF. Educação financeira nas escolas. [s.d.] Disponível em:

$<$ http://www.aefbrasil.org.br/index.php/programas-e-projetos/educacao-financeira-nas-

escolas/.> Acesso em 30 nov. 2014.

. Estratégia Nacional de Educação Financeira [s.d.]. Disponível em:

<www.vidaedinheiro.gov.br/docs/PlanoDiretorENEF.pdf>. Acesso em 02 dez. 2014.

Quem somos e o que fazemos. [s.d.] Disponível em:

<http://www.vidaedinheiro.gov.br/pagina-29-quem_somos_e_o_que_fazemos.html〉. Acesso em 02 dez. 2014.

GREMAUD, Amaury Patrick; VASCONCELLOS, Antonio Sandoval de; TONETO JUNIOR, Rudinei. Economia brasileira contemporânea. 6a. Ed. São Paulo: Atlas, 2005.

HOJI, Masakazu. Finanças da família: O caminho para a independência financeira. $2^{\mathrm{a}}$. Ed. São Paulo: Cia. dos Livros. 2010.

Instituto Brasileiro de Geografia e Estatística (IBGE). População brasileira envelhece em ritmo acelerado. 2008. Disponível em:

<http://saladeimprensa.ibge.gov.br/noticias?view=noticia\&id=1\&busca=1\&idnoticia=1272>. Acesso em 07 fev. 2014.

PNAD - Pesquisa Nacional por amostra de domicílios: Brasil e síntese de indicadores em 2013. 2014. Disponível em:

<.http://www.ibge.gov.br/home/presidencia/noticias/imprensa/ppts/00000018883109232014310 419410583.pdf>. Acesso em 07 fev. 2015.

MAIO JUNIOR, Humberto. "Só quem poupa enriquece”. In: Revista Exame. São Paulo, v.10, n.1066, p. 127, 2014.

LAGO, Luiz Aranha Corrêa. A moeda metálica em perspectiva Histórica: Notas em torno de uma exposição - 1a Parte: De cerca de 600 a.C ao Séc. XV d.C. 2004. Disponível em: <http://www.econ.puc-rio.br/pdf/td481.pdf>. Acesso em 30 set. 2014.

LOPES, João do Carmo. ROSSETTI, José Paschoal. Economia Monetária. $6^{\mathrm{a}}$. Ed. São Paulo: Editora Atlas, 1993. 
MACEDO JUNIOR, Jurandir Sell. A árvore do dinheiro: guia para cultivar a sua independência financeira. $6^{\text {a }}$. Ed. Rio de Janeiro: Elsevier, 2010.

MARTELLO, Alexandro. Endividamento das famílias soma $46 \%$ da renda em julho, informa $B C$. Disponível em <http://g1.globo.com/economia/seu-

dinheiro/noticia/2014/09/endividamento-das-familias-soma-46-da-renda-em-julho-informabc.html>. Acesso em 03 dez. 2014.

MARTINS, Ana Quitéria Nunes Martins. A Formação da Estratégia Nacional de Educação Financeira do Governo Brasileiro. 2013. Dissertação de Mestrado. Escola Nacional de Saúde Pública Sérgio Arouca. Rio de Janeiro. Disponível em:

<http://bvssp.icict.fiocruz.br/lildbi/docsonline/get.php?id=3746>. Acesso em 01 fev. 2015.

MARTINS, José Pio. Educação Financeira ao Alcance de todos: adquirindo conhecimentos financeiros em linguagem simples. 1 $^{\text {a }}$. Ed. São Paulo: Fundamento Educacional, 2004.

MELLO, R. M. Gestão Financeira pessoal de funcionários com emprego estável: Funcionários do Banco XS S.A. Trabalho de conclusão de curso (Bacharel). Universidade Federal do Rio Grande do Sul, Porto Alegre. 2006.

MONTEIRO, Luciana Amorim. Moeda eletrônica - Conceitos e protocolos de segurança. 1998 Disponível em: <http://www.cic.unb.br/ rezende/trabs/e-moeda.htm>. Acesso em 02 out. 2014.

OCDE. What we do and how. [s.d.] Disponível em:

<http://www.oecd.org/about/whatwedoandhow/>. Acesso em 02 dez. 2014.

INEF progress report on Financial Education. 2014. Disponível em:

$<$ http://www.oecd.org/daf/fin/financial-education/OECD-INFE-Fin-Ed-G20-2014-ProgressReport.pdf.>. Acesso em 02 dez. 2014.

OECD's Financial Education Project. 2004. Disponível em:

<http://www.oecd.org/finance/financial-education/33865427.pdf>. Acesso em 03 jan. 2015.

Recommendation on Principles and Good Practices for Financial Education and

Awareness. 2005. Disponível em: <http://www.oecd.org/finance/financialeducation/35108560.pdf >. Acesso em 03 jan. 2015.

PRADO, Rosane de Souza. Educação Financeira no ensino fundamental I. 2013. Monografia (Licenciatura em Pedagogia). Universidade do Estado do Rio de Janeiro, Faculdade de Formação de Professores. 2013.

PORTAL BRASIL. Educação financeira chegará a escolas públicas até 2015. 2014. Disponível em <http://www.brasil.gov.br/educacao/2014/05/educacao-financeira-chegara-aescolas-publicas-ate-2015>. Acesso em 06 mai.2014.

POTRICH, Ani Caroline Grigion; VIEIRA, Kelmara Mendes, CERETTA, Paulo Sergio. "Nível de alfabetização financeira dos estudantes universitários: afinal, o que é relevante?". In: Revista Eletrônica de Ciência Administrativa, v. 12, n.3, p.314-333, 2013.

REVISTA EXAME. 2014. O consumidor se deu mal. São Paulo, v.17, n.1073, p. 111. 
REVISTA VEJA. 2014. Educação Financeira desafia escolas, aponta OCDE. Disponível em: < http://veja.abril.com.br/noticia/educacao/educacao-financeira-desafia-escolas-aponta-ocde>.

Acesso em 02 fev. 2015.

ROBERT , Jozsef. A origem do Dinheiro. 2a . Ed: São Paulo: Global Editora, 1989.

SÁ, Ilydio Pereira de. A educação matemática crítica e a matemática financeira na formação de professores. 2012. Tese (Doutorado em Educação Matemática). Universidade Bandeirante de São Paulo, SP.

SÁNCHEZ GAMBOA, Silvio. Pesquisa em educação: métodos e epistemologias. $2^{\mathrm{a}}$. Ed. Chapecó: Argos, 2012.

SANDRONI, Paulo. Dicionário de economia do século XXI. $6^{\mathrm{a}}$. Ed. Rio de Janeiro: Record, 2010.

SERASA EXPERIAN. Jovem é o perfil que menos controla a vida financeira. 2014. Disponível em: 〈http://www.serasaconsumidor.com.br/jovem-e-o-perfil-que-menos-controla-a-vidafinanceira/>. Acesso em 22 out. 2014.

Indicador de Educação Financeira. 2014. Disponível em:

<http://serasaconsumidor.com.br/indef/>. Acesso em 23 nov. 2014.

Inadimplência do consumidor fecha 2014 com alta de 6,3\%, revela Serasa Experian.

2015. Disponível em: <http://noticias.serasaexperian.com.br/inadimplencia-do-consumidorfecha-2014-com-alta-de-63-revela-serasa-experian/>. Acesso em 22 jan. 2015.

. Inadimplência do primeiro semestre teve alta de 16,4\%. 2015. Disponível em:

$<$ http://www.serasaconsumidor.com.br/inadimplencia-do-consumidor-fecha-o-primeirosemestre-do-ano-com-alta-de-164-revela-serasa-experian/>. Acesso em 24 nov. 2015.

SEVERINO, Antônio Joaquim. Metodologia do trabalho científico. $23^{\mathrm{a}}$. Ed. São Paulo: Cortez, 2007.

SILVA, Eduardo D. Gestão em finanças pessoais: uma metodologia para se adquirir educação e saúde financeira. Rio de Janeiro: Qualitymark, 2004.

SILVA, Jônatas Rodrigues. Método para a educação financeira: da sensibilização à ação. São Paulo: All Print Editora, 2012.

SILVA, Mônica Queiroz. Educação Financeira no Ensino Superior: Estudo com alunos dos cursos de Direito e Administração da UEMG - Frutal. 2015. Dissertação de Mestrado em Educação. Universidade de Uberaba, MG.

SPC BRASIL. Oito em cada dez brasileiros não sabem controlar as próprias despesas mostra estudo do SPC Brasil. 2014. Disponível em:

<https://www.spcbrasil.org.br/imprensa/noticias/340-

oitoemcadadezbrasileirosnaosabemcomocontrolaraspropriasdespesasmostraestudodospcbrasil>.

Acesso em 22 abr. 2014. 
.52\% dos brasileiros fizeram alguma compra por impulso nos últimos três meses, revela SPC Brasil. 2014. Disponível em: <https://www.spcbrasil.org.br/imprensa/pesquisas/397-

52dosbrasileirosfizeramalgumacompraporimpulsonosultimostresmesesrevelaspcbrasil $>$. Acesso em 07 dez. 2014.

- Maioria dos brasileiros usa o crédito para realizar compras imediatistas, aponta relatório do SPC Brasil. 2015. Disponível em:

<https://www.spcbrasil.org.br/imprensa/noticia/591-

maioriadosbrasileirosusaocreditopararealizarcomprasimediatistasapontarelatoriodospcbrasil > Acesso em 03 fev. 2015.

STERVENSON, William. J. Estatística Aplicada à Administração. São Paulo: Haper \& Row do Brasil, 1981.

TOLOTTI, Márcia. As armadilhas do consumo: acabe com o endividamento. Rio de Janeiro: Elsevier, 2007. $4^{\mathrm{a}}$. Reimpressão.

TOBIAS, Andreza Maria Neves Manfredini; CERVENY, Ceneide Maria de Oliveira. Educação Financeira na família: como falar de dinheiro com crianças. São Paulo: Roca, 2012.

VASCONCELLOS, Marco Antonio Sandoval de, GARCIA, Manuel Enriquez. Fundamentos da Economia. 2a ${ }^{\text {a }}$ Ed. São Paulo: Editora Saraiva, 2005.

VIDA E DINHEIRO. Conceito de educação financeira no Brasil. [s.d.] Disponível em: <http://www.vidaedinheiro.gov.br/pagina-23-no-brasil.html>. Acesso em 02 dez. 2014.

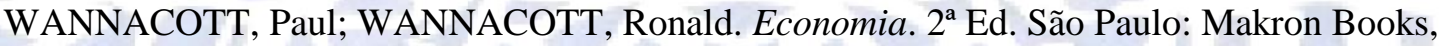
1994. 